Hiram E. Fitzgerald · Kai von Klitzing

Natasha J. Cabrera · Júlia Scarano de Mendonça

Thomas Skjøthaug Editors

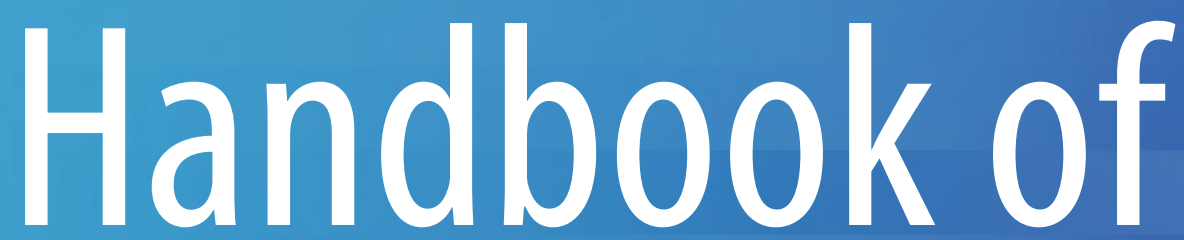

Fathers and

Child

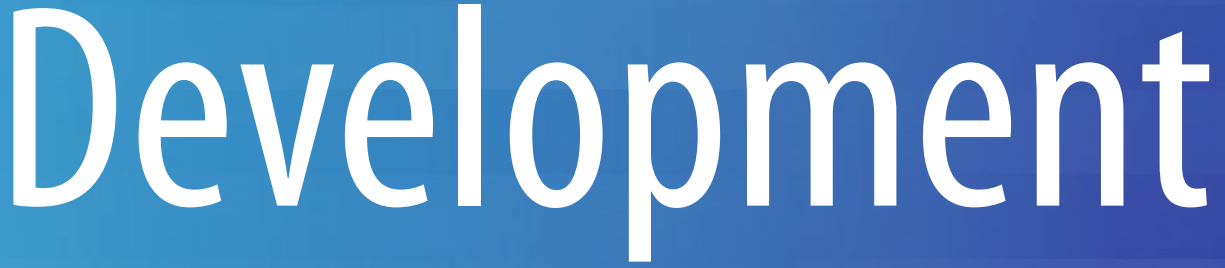

Prenatal to Preschool

Springer 
Handbook of Fathers and Child Development 
Hiram E. Fitzgerald

Kai von Klitzing

Natasha J. Cabrera

Júlia Scarano de Mendonça

Thomas Skjøthaug

Editors

Handbook of Fathers

and Child Development

Prenatal to Preschool

基 Springer 


\section{Editors}

Hiram E. Fitzgerald

Michigan State University

East Lansing, MI, USA

Natasha J. Cabrera

University of Maryland

College Park, MD, USA

Thomas Skjøthaug

Division of Mental Health

Akershus University Hospital HF

Lørenskog, Norway

\author{
Kai von Klitzing \\ Department of Child and Adolescent \\ Psychiatry \\ University of Leipzig \\ Leipzig, Sachsen, Germany
}

Júlia Scarano de Mendonça

Graduate Program in Educational

Psychology

Centro Universitário FIEO

Osasco, São Paulo, Brazil

ISBN 978-3-030-51026-8
https://doi.org/10.1007/978-3-030-51027-5

(C) Springer Nature Switzerland AG 2020

This work is subject to copyright. All rights are reserved by the Publisher, whether the whole or part of the material is concerned, specifically the rights of translation, reprinting, reuse of illustrations, recitation, broadcasting, reproduction on microfilms or in any other physical way, and transmission or information storage and retrieval, electronic adaptation, computer software, or by similar or dissimilar methodology now known or hereafter developed.

The use of general descriptive names, registered names, trademarks, service marks, etc. in this publication does not imply, even in the absence of a specific statement, that such names are exempt from the relevant protective laws and regulations and therefore free for general use.

The publisher, the authors, and the editors are safe to assume that the advice and information in this book are believed to be true and accurate at the date of publication. Neither the publisher nor the authors or the editors give a warranty, expressed or implied, with respect to the material contained herein or for any errors or omissions that may have been made. The publisher remains neutral with regard to jurisdictional claims in published maps and institutional affiliations.

This Springer imprint is published by the registered company Springer Nature Switzerland AG The registered company address is: Gewerbestrasse 11, 6330 Cham, Switzerland 


\title{
The Characteristics and Lived Experiences of Modern Stay-at- Home Fathers
}

\author{
Shawna J. Lee, Joyce Y. Lee, and Olivia D. Chang
}

\section{Demographic Data}

\section{Work and Family Responsibility Patterns Among Men and Women in the USA}

In the last several decades, there have been significant changes in work-life balance for men and women in the USA. Between 1978 and 2018, the rate of working-age women's labor participation increased from $50 \%$ to $57.1 \%$, whereas the rate of working-age men's labor participation decreased from $77.9 \%$ to $69.1 \%$ (US Bureau of Labor Statistics, 2018). In 2018, nearly two thirds $(65.1 \%)$ of women with children under the age of 6 and over half (59.6\%) of women with children under the age of 3 were working for pay (US Bureau of Labor Statistics, 2019). Parallel to the increasing number of working mothers is the decreasing number of mothers staying home and taking care of their children as their primary caregivers. For instance, in 2016, less than a third (27\%) of women with working husbands were considered stay-at-home mothers (SAHMs) compared to close to $40 \%$ of women in 1970 (Livingston, 2018).

S. J. Lee $(\varangle)$ - J. Y. Lee · O. D. Chang School of Social Work, University of Michigan, Ann Arbor, MI, USA

e-mail: shawnal@umich.edu

\section{Definitions and Numbers of Stay-at- Home Fathers}

The increase in the number of mothers who are in the workforce full-time has not resulted in a proportionate increase in the number of fathers who are the primary caregivers for their children. This could be due in part to the US Census Bureau's narrow definition of a stay-at-home father (SAHF). The US Census Bureau defines a SAHF as a married man with a child or children younger than 15 years old who has remained outside of the labor force for at least 1 year to primarily care for their children while their wives worked outside of the home (US Bureau of Labor Statistics, 2018). Using this narrow definition of a SAHF, which excludes many family and caregiving arrangements in which men are the primary caregiver to their children, the US Census estimated that there were 190,000 SAHFs in 2018 (US Census Bureau, 2018). Although this is more than double the 93,000 reported SAHFs in 2000 (US Census Bureau, 2018), the majority (79.8\%) of stay-at-home parents are mothers, and about one fifth $(20.2 \%)$ of stay-at-home parents are fathers (Terrazas, 2018). Studies suggest that the US Census Bureau's definition likely underestimates the number of SAHFs by not accounting for fathers who work part-time but are still primary caregivers to children, report other reasons for staying at home, or have been home for less than a year (Latshaw, 2011; Livingston, 2018). 
As noted above, the US Census Bureau utilizes a narrow definition of a SAHF that seemingly excludes multiple categories of men who are functionally serving as the primary caregivers to their children, including single fathers, gay fathers, fathers with children who are older than 15 , fathers who are looking for paid work, and fathers who worked for some hours in the past year (Burkstrand Reid, 2012). Many SAHFs may be working part-time or for a few hours in the past year, but still maintain the role of primary caregiver relative to their partner's career and employment. Again, the US Census definition of a SAHF would seemingly exclude these men from being included as stay-at-home parents. It is important to note that such limited definitions used by the US Census Bureau restrict the diversity (e.g., race/ethnicity, SES) of who is officially defined as a stay-at-home parent.

To more accurately assess the number of fathers who may be primary caregivers to their children, it is important to consider alternative definitions of SAHFs that use broader parameters. The Pew Research Center defined SAHFs to include fathers of older children, fathers in relationship statuses other than marriage, fathers who did not work for pay in the last year regardless of the reason, and fathers with spouses or partners with other employment statuses other than currently working for pay (Livingston, 2018). Using this alternative definition, statistics from the Pew Research Center suggested that there were approximately four million SAHFs in 2016 (Livingston, 2018). This is a much higher number of SAHFs than the estimates provided by the US Census Bureau. The Pew Research Center further suggested that the number of SAHFs has been increasing overall, nearly doubling from $4 \%$ in 1989 to $7 \%$ in 2016. While fathers remain a substantially smaller proportion of the stay-athome parent population as compared to mothers, the Pew Research Center data suggested that the number of SAHFs is continuing to increase over time, whereas the number of SAHMs appears to be static (Livingston, 2018).

Coming up with an optimal definition of SAHFs is challenging (Burkstrand Reid, 2012; Livingston, 2018). Even with its broader param- eters, the Pew Research Center's definition may omit important categories of fathers, such as single-parent SAHFs and fathers who are primary caregivers but who are employed part-time by working a few hours in the prior year. Further, it is unclear whether the Pew Research Center is accounting for SAHFs who may be in same-sex relationships. Although there has been progress in more inclusive definitions of SAHFs, it is likely that the actual number of SAHFs is still underestimated. It is notable that reliable tracking of SAHFs began relatively recently (Livingston, 2018). On the whole, there is much need for additional research on the characteristics and needs of SAHF families and, more broadly, on families in which fathers assume the role of primary caregiver.

\section{Reasons for the Increased Number of Stay-at-Home Fathers}

Even though SAHFs are far fewer in number than SAHMs, the increase in SAHFs may be interpreted as representing a shift in the notions of fatherhood. For example, there has been a significant increase in fathers' involvement in direct caregiving and housework overall. Traditional notions of gender roles among heterosexual married couples, with men seen as "breadwinners" and women seen as caregivers, have shifted over time. Women's educational achievement has increased, and at least for some professions, there have been decreases in the gender pay gap. In addition, scholars have noted that the Great Recession had an impact on the labor market. Below we discuss these factors and how they may relate to the rise of SAHFs.

Per the first point, fathers, in general, have more than tripled the amount of time they spend on childcare in a given week. In 1965, fathers spent approximately 2.5 hours per week on childcare. By 2016, that number had increased to 8 hours per week (Parker \& Livingston, 2019). Combining hours for both housework and caring for children, fathers have increased the proportion of time they put into these activities from $13 \%$ in 1965 to $30 \%$ in 2016 (Parker \& Livingston, 2019). 
Regardless of whether they are working or not, women still do the majority of housework and childcare (Parker \& Livingston, 2019). Even so, these statistics suggest that fathers today are interested in being hands-on parents and involved in activities that are related to rearing their children (e.g., bathing, feeding) and creating an environment that promotes their well-being. Men who become SAHFs are likely to embody these trends.

In 2016, approximately a quarter of SAHFs (24\%) reported that they chose to stay home specifically to care for their family or home (Livingston, 2018) This group experienced the largest increase in number among SAHFs between 1989 and 2012 compared to SAHFs who provided other reasons for becoming primary caregivers (e.g., unable to find work, illness) (Livingston, 2018). This suggests that stereotyped roles of mothers as the primary caregivers and fathers as the main breadwinners may no longer be true for many American families. Fathers are now seen to have roles that go beyond the breadwinner, disciplinarian, and male role model. Fathers are now seen in a more complex and nuanced manner to embody roles that include care provider, teacher, play companion, parenting role model, and supportive partner (Yogman \& Garfield, 2016).

At the same time, mothers' roles have shifted. While traditional gender roles emphasized the mother as a primary caregiver and thus often a stay-at-home parent, in today's contexts, mothers are seen as both primary caregivers and workers. It is important to note that these conceptualizations of "traditional" gender roles have been bounded by race and class. That is, poor women and race and ethnic minority women historically have been expected to provide for their families through employment, as well as to serve as primary caregivers to children, both their own and others' children (McGinn \& Oh, 2017). Even so, some have argued that men's traditional role as the primary breadwinner has been resilient particularly to class expectations over time (Ashwin \& Lytkina, 2004; Chesley, 2011).

In our current era, socioeconomic occurrences like the Great Recession in 2008 may have contributed to an increase in SAHFs. The Pew Reserach Center reported that the overall propor- tion of stay-at-home parents increased from $15 \%$ in 2000 to $20 \%$ in 2010 due, in part, by parents who were staying home because they could not find jobs (Livingston, 2018). This echoes earlier shifts in which it appears that unemployment and the inability to find work, as opposed to staying home to focus on family caregiving needs, is one key factor that may contribute to fathers' decisions to stay home (Kramer, Kelly, \& McCulloch, 2013). This seems to have been particularly true for SAHFs. A third of them reported that they were staying for reasons related to unemployment in the aftermath of the Great Recession in 2010 (Livingston, 2018).

Along with changing gender norms and the Great Recession is the growth in women's educational achievement, their involvement in the workforce, and the decreasing gender pay gap. Between 2000 and 2017, educational achievement rates for 25- to 29-year-olds were higher for females than for males (National Center for Education Statistics, 2018). In particular, the gender gap increased for those who have attained higher education (US Census Bureau, 2019), with 25- to 29-year-olds who completed an associate's degree or higher experiencing an increase in the gender gap from 5\% in 2000 to $10 \%$ in 2017. Those who completed a bachelor's or higher degree experienced an increase in the gender gap from 2\% in 2000 to $7 \%$ in 2017 (National Center for Education Statistics, 2018). As women's educational outcomes improved, so did their ability to secure higher-income jobs, obtain promotions, and earn enough money to sustain their families. The decrease in gender gap pay (women between the ages of 25 and 34 earned $67 \%$ in 1980 of what men earned vs. $89 \%$ in 2018) suggests that families may have more flexibility and opt for arrangements whereby mothers are "breadwinners" and fathers are primary caregivers of children.

\section{Sociodemographics of Stay-at-Home Fathers}

Even though the definition of SAHFs used by the US Census Bureau is narrow and likely excludes families in which fathers are the primary caregiv- 
ers for their children, it is worthwhile to examine sociodemographic characteristics of SAHFs. In addition to the fact that SAHFs are a growing subgroup of parents, they may reflect a group of fathers who are redefining traditional gender norms, roles, and beliefs. Between 2015 and 2017, which is the most recent data available, the majority of SAHFs were under 45 years of age. This makes sense, given that this age group of men is also more likely to have young children at home when compared to older men (US Census Bureau, 2018). When looking at a recent slice of time (2015-2016), Millenial men (i.e., men born between 1981 and 1996) were more likely to be SAHFs between the ages of 25 and 35 years old, as compared to Generation X men (i.e., men born between 1965 and 1980) when they were the same age in 1999 and 2000 (Livingston, 2018). A little less than half of the SAHFs (44\%) reported having at least one child under the age of 5 years old that they were taking care of primarily at home (Livingston, 2018).

Most SAHFs were white (49\%), followed by Hispanic (21\%), Black (15\%), and Asian and Pacific Islander (11\%) (Livingston, 2018). Over half of SAHFs had a high school degree or less $(53 \%)$, followed by some college $(22 \%)$ and a bachelor's degree or more (25\%). The majority of SAHFs reported being married to a working spouse (61\%), and the remaining SAHFs reported being married with a non-working spouse $(15 \%)$, cohabiting (15\%), or single (9\%). In 2018, the majority $(62.4 \%)$ of married couples with children under 18 years where only the wife was in the labor force had a family income of $\$ 50,000$ or more (US Census Bureau, 2018).

In 2016, men reported the following reasons for becoming SAHFs: $40 \%$ ill or disabled, $24 \%$ to take care of their home or family, $11 \%$ retired, $8 \%$ in school, and $7 \%$ unable to find work (Livingston, 2018). Although general demographics are presented above, it is important to note that the profiles of SAHFs look different depending on the reasons they state for staying at home. For instance, SAHFs who reported staying home for reasons other than caring for their children or family were likely to have lower educational attainment, more likely to live in poverty, more likely to be married with a non-working spouse or be single, less likely to have a child younger than 5 years old, and older in age compared to SAHFs who reported staying home for their children and family (Livingston, 2018). Collectively, these suggest that SAHFs are a diverse group of fathers and that their sociodemographic characteristics and reasons for becoming a stay-at-home parent vary.

\section{Review of Qualitative and Quantitative Research on the Lived Experiences of SAHFs}

This section reviews qualitative and quantitative literature of the lived experiences of SAHFs. Overall, being a SAHF is associated with both positive and negative experiences. Some studies highlight the positive experiences of SAHFs, such as the emotional benefits that fathers may gain from being the primary caregiver of their children and the ability to maintain better overall family work-life balance when one parent is staying home. Other studies emphasize the negative experiences of SAHFs, such as feelings of isolation and loneliness and the challenges men experience when they occupy a nontraditional gender role. We start by delineating the themes found in qualitative literature, and then introduce quantitative research findings. We try to provide an overview of both positive and negative experiences; however, notably the literature seems skewed toward reporting on the challenges that SAHFs experience.

\section{Qualitative Literature on the Lived Experiences of SAHFs}

\section{Gender Roles, Masculine Identity, and Gender}

Role Conflict Gender role conflict is defined as a "psychological state in which socialized gender roles have negative consequences for the person or others." Gender role conflict "occurs when rigid, sexist, or restrictive gender roles" contribute to the devaluation of the self (O'Neil, 2013). Experiencing gender role conflict can be harmful 
to men's mental health and well-being, contributing to stress, anxiety, and depression (O'Neil, 2013). In the context of the current literature review, gender role conflict theory applies to our understanding of SAHFs as the potential for conflict between a stereotypical masculine gender role ("breadwinner") and the lived experience of being a primary caregiver of young children ("caregiver"). The caregiver role may conflict with masculine norms, either at the individual or societal level, and thus create the possibility for poorer mental health and well-being among SAHFs.

Studies link SAHFs' experiences to gender role conflict. Some SAHFs have reported feelings of emasculation, decreased marital satisfaction, and less optimal well-being (Rochlen \& Mahalik, 2004; Snitker, 2018; Solomon, 2014). Factors such as the stress of parenting and taking care of the home, social discrimination, feelings of failure in the caregiving role, and feelings of frustration may contribute to gender role conflict as well (Barnett \& Hyde, 2001). Researchers have noted double standards related to gender and parenting. While it is often viewed as important for parents to be present and available for their children, for men this may contradict traditional masculine gender norms, particularly norms related to breadwinning (Deutsch \& Saxon, 1998). Such double binds may apply to both mothers and fathers, yet mothers may feel a stronger pull in the caregiving direction while fathers are pulled toward breadwinning norms.

SAHFS have reported frustration with having to justify their caregiving roles to other people who might see them and their responsibilities as abnormal or questionable (Rochlen, McKelley, Suizzo, \& Scaringi, 2008). Some SAHFs have identified gender policing or sanctions that are applied to behaviors that are seen by others as deviant or unsuited to men (Solomon, 2014). Fathers may feel shamed for their roles when others relegate them to being "Mr. Mom" or simply "babysitting" on their day off from work (Snitker, 2018; Steinhour, 2018). SAHFs have also identified the challenges of navigating their caregiving roles in a social and cultural context of hege- monic masculinity which considers the ideal forms of masculinities to be ones that establish men's dominant role within the patriarchal society of the USA (Connell, 1995; Doucet, 2004; Snitker, 2018). Relatedly, men are more likely than women to be criticized for leaving work to care for their sick children and yet also more likely to be criticized if they are perceived to have chosen to spend more time with their children than friends (Deutsch \& Saxon, 1998).

SAHFs employ different strategies to navigate traditional gender norms and even construct alternative masculinities that accomodate their role as a primary caregiver. For example, one study found that SAHFs incorporated caregiving activities into their masculine identities, reconstructing their masculine identity so that caring for their children is seen as a masculine activity, for example, considering the caregiving role as providing for their family in nonmonetary fashion (Lee \& Lee, 2018). This finding echoes themes from other research. A quantitative study of hundreds of media stories suggested that men who are SAHFs not only reconstruct their masculine identity to include caregiving but may adapt their behaviors in ways that accommodate both their "caregiving" and "masculine" identities; in other words, most SAHFs did not "fully reject" traditional masculine norms either in beliefs or behavior (Burkstrand Reid, 2012). SAHFs also reported developing respect for caregiving as legitimate work, which in many ways stands in contrast to prevailing norms (Lee \& Lee, 2018).

An additional benefit to the SAHF role is that it may contribute to better family relationships. Although research on this topic is limited, one qualitative study of the dynamics in SAHF families found that the majority of the working mothers in SAHF families reported positive parent-child relationships, strong parenting cohesion, and enhanced family quality time as a result of having a stay-at-home partner (Rushing \& Powell, 2015). According to mothers in this study, both the mother-child and father-child relationships were perceived to be positive because of the SAHF role. Mothers felt more support from their partner and reported a more egalitarian approach to parenting. They also indi- 
cated that they were able to have more quality time at home as a result of their SAHF partner having a routine during the day (Rushing \& Powell, 2015). However, one large quantitative study, discussed in more detail below, suggested that parents were less satisfied with their relationships after the transition from dual-earner or male-breadwinner household to femalebreadwinner household (Blom \& Hewitt, 2020).

\section{Employment and Work-Life Family} Conflict Many SAHFs have voiced the desire to return to paid work in the future, but also note concerns about their ability to successfully obtain and adjust to employment after spending time away from the workforce (Caperton, Butler, Kaiser, Connelly, \& Knox, 2020). One study indicated that the majority (over $80 \%$ ) of SAHFs intended to stay in their roles on a short-term basis and planned to return to the workforce within 5 years (Latshaw, 2011). However, the desire to return to the workforce is accompanied by fathers' concerns related to damaging their careers by taking gap years to care for their children. As a case in point, a SAHF reported that becoming a primary caregiver is committing "professional suicide" (Latshaw, 2011). To allay these concerns, some SAHFs also pursued parttime employment while caring for their children. Latshaw (2011) found that $60 \%$ of SAHFs in her study brought in some form of income during their tenure as primary caregivers. Reasons for their pursuit of employment included the desire to contribute financially to their families, as well as a desire to ease the sense of isolation that came with the primary caregiving role.

Social Support and Social Isolation Perhaps one of the most well-noted challenges that SAHFs face is isolation and a lack of social support. Although social isolation is not an experience limited to SAHFs (e.g., SAHMs; Parry, Glover, \& Mulcahy, 2013), many researchers note that, compared to mothers who stay home, fathers appear to have fewer resources to lessen their experiences of loneliness. In a study that compared the experiences of SAHM and SAHF families, SAHFs reported greater loneliness and were more isolated and less active in the community (Zimmerman, 2000). This may be explained by the disconnection of SAHFs to their working male peers, as well as their feeling of disconnection from SAHMs, which leaves SAHFs isolated and alone relative to their SAHM peers (Snitker, 2018; Zimmerman, 2000). Indeed, it is also not uncommon for working fathers who become SAHFs to experience a loss of social networking with coworkers and disapproving family members and friends. Being explicitly excluded from or not feeling comfortable or understood as a SAHF in SAHM groups (e.g., playdate groups, support groups) continues to contribute to and explain the high levels of loneliness and social isolation reported by SAHFs (Cameron, 2001; Snitker, 2018).

As Caperton et al. (2020) suggest, the isolation and lack of social support commonly experienced by SAHFs is worthy of greater attention given that such conditions can place SAHFs at heightened risk for poorer psychological outcomes (e.g., paternal depression). This is concerning given that even nontraditionally masculine men, such as SAHFs, report difficulty seeking professional help for mental health concerns (Caperton et al., 2020). That said, one mechanism by which SAHFs have found a supportive and empathetic community is through online and social media groups created by and for SAHFs (Ammari \& Schoenebeck, 2016). Such groups include local SAHF Facebook groups, the National At-Home Dad Network, and the At-Home Dads Convention, to name a few.

Education and Resources for Fathers Given that on average SAHFs are expected to be responsible for a greater share of childcare than fathers who are working, and thus they may play a bigger role in the health and well-being of their children (Feinberg, Jones, Kan, \& Goslin, 2010), it is vital that educational resources are widely available and accessible for SAHFs. Yet, there are relatively few options for SAHFs - and all fathers in general - related to adequate and effective parenting education 
(May \& Fletcher, 2013). According to Goodman (2005)'s review of qualitative studies on new fatherhood, there appears to be a need to create greater male-only parent education classes in order for fathers to develop confidence in a space where they are being compared to their female partners. While male-only groups can be effective for parent education for men, SAHFs currently report that there are still gaps in their accessibility to such education (Henry, 2017). Thus, it is not surprising that social media and online groups have become popular forums for fathers to not only form social connections, but to also exchange parenting information and advice from one father to another (StGeorge \& Fletcher, 2011). Specifically, StGeorge and Fletcher (2011) found that in an online chat room used by fathers of young infants and children, apprehensions about fatherhood and difficulties for new fathers emerged as the second and third most discussed topics, following the need for new-fathers' groups. Besides online discussions, other forms of media, such as YouTube channels, have attracted the attention of many fathers seeking information and insight into parenting. For example, Beleaf in Fatherhood is a YouTube channel created by Glen Henry (Henry, 2017), to share his experiences of being a new father "knowing nothing at all" about being a SAHF, to today, a father of five children. Moreover, as a Black SAHF, Henry's videos illustrate the unique experiences of being a SAHF of color. Evidently, although father-formed online forums, YouTube channels, and Facebook groups are important and valuable, it is necessary to continue to modify and expand formal parent education for fathers and SAHFs.

\section{Quantitative Literature}

There are relatively few quantitative studies on SAHFs and their experiences. Below we review a number of quantitative studies that examine predictors of SAHF family formation, SAHFs' experiences, and SAHFs' mental health.

\section{Predictors of SAHF Family Formation and} Experiences Using secondary data analysis, Kramer and Kramer (2016) sought out to examine predictors that contribute to the rise in SAHF families. The researchers used data from the National Longitudinal Surveys of Youth and the Current Population Survey and found that unemployment rates were linked with SAHF families that is, when unemployment rates increased, so did the number of SAHFs. The probability of a SAHF arrangement was greater when mothers had more education compared to fathers. Gender ideology was also predictive of SAHF family formations, with men's egalitarian views associated with greater likelihood of becoming a SAHF. More egalitarian views were associated with men reporting that they became SAHFs primarily to take care of their children and not because they were unable to work (Kramer \& Kramer, 2016). Kramer, Kelly, and McCulloch (2015) used the Current Population Survey data from 1976 to 2009 to compare characteristics and proportions of SAHF, SAHM, and dual-earner households. They found that mothers in SAHF households generally had higher education levels than their husbands and they experienced the sharpest increase in education over time compared to their counterparts in other households. Further, those SAHF families, especially those where the father became a SAHF to primarily care for his children and not because he could not find employment, were closing the income gap with SAHM households over time.

Rochlen et al. (2008) collected survey data from 213 SAHFs to examine predictors of relationship satisfaction, psychological well-being, and life satisfaction among SAHFs. SAHFs reported moderate to high levels of relationship and life satisfaction and moderate to low levels of psychological distress compared to college-aged and adult males. SAHFs also reported high levels of parental self-efficacy. Social support, high levels of parenting self-efficacy, and low levels of conformity to traditional masculine gender norms were associated with positive adjustment to the SAHF role. A recent study using data from the Household, Income and Labour Dynamics 
household panel survey in Australia $(\mathrm{n}=11,986)$ found that both men and women became less satisfied in their relationships when they transitioned from dual-earner or male-breadwinner households to female-breadwinner households (Blom \& Hewitt, 2020). Interestingly, participants were most satisfied in their relationships when they were in male-breadwinner and femalehomemaker households, suggesting that on average men and women are still pulled towards traditional gender norms and the perceptions of their relationship quality are informed by whether their households conform to these traditional norms (Blom \& Hewitt, 2020).

Rochlen, McKelley, and Whittaker (2010) used data from a survey to examine SAHFs' reasons for entering their role and stigma-related experiences. Economic factors (e.g., partner earns more money than they do), strong parenting values (e.g., the importance of one parent at home), and pragmatic reasons were the most common reasons for becoming a SAHF. Half of the SAHFs in the study reported experiencing stigma, mostly in interactions with SAHMs. The most common reasons SAHFs reported for perceived stigma included people's ignorance or unfamiliarity with their roles (e.g., most people are not familiar with or do not have experience with males serving as a primary caregiver), opposing attitudes about gender roles (e.g., people's general prejudice toward men in traditionally feminine roles), and distrust or discomfort (e.g., individuals' general discomfort with men around children and assuming that men are harmful to children). Those who reported stigmarelated experiences had lower levels of social support than SAHFs who did not report such experiences.

Mental Health There are few studies that have rigorously examined the mental health of SAHFs. As noted earlier, SAHFs are on average living in households that have higher levels of education and income when compared to the general US population; higher levels of education and income are correlated with better mental health. Therefore, on the whole, SAHFs may be expected to have relatively high levels of mental health. At the same time, qualitative research suggests that SAHFs are small in number and occupy a niche that may contribute to feelings of gender role conflict. There are few resources and supports available to SAHFs, contributing to the potential for poorer well-being for SAHFs.

Rochlen and colleagues' (2008) study of 213 self-identified SAHFs provides some insight into these dynamics. Their study consisted of white $(93 \%)$, middle- and upper-income, married SAHFs. Although the sample was not diverse, it seems to reflect other studies of SAHFs. Rochlen et al. (2008) found that SAHFs had levels of well-being that were comparable to other studies of men. The SAHF respondents reported levels of life satisfaction and well-being that appeared to be similar to or better than other published data on samples with similar socioeconomic status and education levels. That said, it is not clear that the samples used for comparison to the SAHFs in the survey were valid, given that the comparisons were drawn from studies conducted with different populations.

One study suggestsed that men who become SAHFs may experience higher levels of depression symptoms compared to women who become SAHMs (Kramer \& Pak, 2018). This study appears to be the most rigorous to date to examine how changes within the family may relate to mothers' and fathers' well-being. This study examined how change in status, in this case, a move from providing family income to becoming a stay-at-home parent, influenced depression symptoms among mothers and fathers. The researchers found that among fathers, but not mothers, moving to a stay-athome parent status was associated with more depression symptoms. Interestingly, this effect was not moderated by fathers' greater beliefs in egalitarian gender ideology. The authors suggest that the study results may be interpreted to support the notion that there is tension between traditional gender norms for mothers and fathers vis-à-vis their parenting and working roles, such that shifts in caregiving and parenting roles will have different implications for men and women (Kramer \& Pak, 2018). 


\section{Policy and Intervention Implications}

What can be learned from the example of SAHFs about supporting men and fathers? The experiences of SAHFs may represent one end of the caregiving continuum as men integrate the parenting and caregiver role with other valued identities. Thus, there is much to learn from SAHFs about their specific parenting and wellbeing needs, as well as how to support all men and fathers in the transition to parenthood.

Paternity Leave As stated by Burkstrand-Reid (2012), it stands to reason that if men who are SAHFs "face masculinity constraints while challenging gender norms" in their decision to stay at home to raise their children, then it is likely that many men may face similar gender norm challenges when making decisions to take advantage of family leave policies such as the Family Medical Leave Act (FMLA) or other paternity leave policies offered through the workplace. These decisions are complicated by the fact that the USA is the only industrialized country that does not offer paid parental leave policy for mothers or fathers, and paid parental time off has not been established as a norm in the USA, particularly among fathers. One clear policy implication is to establish a federal paid parental leave policy that is available to all parents in the USA. A recent opinion piece in the New York Times illustrated these complexities. Alexis Ohanian, spouse of world famous tennis star Serena Williams, discussed how important paternity leave was for their family, so that he could care for his wife who suffered serious complications following birth. While his presence at home was critical, he writes of the stigma attached to taking time off as a male caregiver (Ohanian, 2019).

Research supports the benefits of paternity leave. For example, one study showed that more than 2 weeks of paternity leave was associated with better parenting relationship, as well as numerous beneficial outcomes for children, including more frequent father-child involvement, greater father-child closeness, and better father-child communication (Petts, Knoester, \& Waldfogel, 2019). Another study demonstrated unique benefits of paternity leave to low-income families. Paternity leave when a child was born was associated with higher levels of father involvement later in the child's life, when compared to the outcomes of children whose fathers did not take leave (Knoester, Petts, \& Pragg, 2019). Importantly, this study also found that paternity leave is especially beneficial for father involvement in so-called fragile families, in which parents are unmarried at the time of their child's birth. Specifically, "among fathers who were not residing with the mothers, but were romantically involved with them at the time of their child's births, taking leave led to higher levels of father responsibility 1 year after birth compared to the implications of taking paternity leave among married fathers" (Knoester et al., 2019). This research suggested that supporting fathers as caregivers, particularly following birth, may be especially beneficial to vulnerable families. Supporting fathers in this way may make it more plausible for them to take on primary caregiving roles as their children grow older.

\section{Parenting Resources and Support to}

Fathers There are very few parenting resources and education available to SAHFs. Indeed, this problem is not unique to fathers who are primary caregivers. Overall, there are few parenting resources or education available to fathers regardless of the intensity of their caregiving role. Qualitative studies of SAHFs speak to the relative lack of resources and support that SAHFs report being available to them (Lee \& Lee, 2018). Recently, a systematic review found that the overall state of father-inclusive perinatal parent education programs is weak, with few interventions available for fathers within the first year of the child's birth (Lee et al., 2018). Other studies have shown similar results, for example, there are few parenting training programs that can be considered father-inclusive or that involve fathers (Lundahl, Tollefson, Risser, \& Lovejoy, 2008). In sum, most websites and in-person parent education classes focus on meeting the needs of mothers and children with little regard for the fathers' and men's parenting needs and wants. 
An implication is the need for companies and practitioners who work with families to develop and create services and programs that support fathers' unique parenting needs and experiences and to provide SAHFs with support that is comparable to the resources available to SAHMs. SAHFs report that social isolation and lack of support is one of their main concerns, and this is one of the most consistent themes in the qualitative literature. Parent education classes and resources allow for conversations and relationship-building that could help SAHFs combat feelings of loneliness and mental health issues and obtain much needed emotional and social support from fellow parents, fathers, and SAHFs. Father-friendly and father-inclusive parenting resources that are evaluated for their effectiveness could help address this need in the future.

\section{Summary and Key Points}

\section{Research Gaps}

Even as there is growing research on SAHFs and their lived experiences captured in both qualitative and quantitative studies, there are a number of gaps in the literature that future studies should address. The research literature is limited in quantitative studies of the health and well-being of SAHFs. There is lack of representation of diverse fathers and families in the SAHF literature. Nearly all studies of SAHFs focus on fathers' or mothers' experiences, while children's experiences and well-being are largely absent from the literature. Furthermore, there is very little research on SAHFs from an international or global perspective. Thus, a limitation of this literature review is the narrow focus on the USA context of parenting mostly (for exceptions, see Kaplan \& Garner, 2017; Liong, 2017; Merla, 2008; Plantin, Mansson, \& Kearney, 2003). There is likely much to be learned about SAHFs from the experience of men and fathers in other countries; however, very little research exists on this topic. For example, it is possible that in countries that provide more support for paid paternal leave or more support for fathers and parents in general, SAHFs may experience fewer incidents of isolation or gender role conflict (Merla, 2008; Plantin et al., 2003).

\section{Diversity and Representation in the SAHF} Research Literature First, a key limitation of the existing research on SAHFs is the lack of diversity of the SAHF study samples. Many of these studies consist of men who are well educated, white, and from higher-income groups. In many studies, fathers made a voluntary choice to become a primary caregiver, often because a partner had sufficient earnings and career potential to accommodate this choice. For the most part, studies of SAHFs do not capture the experience of male caregivers that do not fit neatly into the definition of a SAHF, and thus research on SAHFs does not capture the experiences of large groups of men who may be primary caregivers to their children but who are not considered SAHFs. As noted earlier, depending on the definition used to define a SAHF, those excluded from the categorizations of SAHF may include single fathers, divorced fathers, gay fathers, and fathers who work part-time for some pay during the year. Even though numerous qualitative studies have allowed individuals to self-identify as SAHFs, rather than using the strict definition followed by the US Census Bureau, the samples tend to be small and unrepresentative (e.g., Caperton et al., 2020; Chesley, 2011; Lee \& Lee, 2018; Rochlen et al., 2008).

Thus, researchers who wish to better understand the experiences of male caregivers to young children, regardless of whether they fit into the SAHF definition, should also consider the experiences of male caregivers who are unmarried, those who have lower income, men who are caregivers because they are unable to obtain or maintain employment work, race and ethnic minority fathers, and those who became a primary caregiver due to an illness or disability. The lived experiences of these SAHFs are rarely investigated in research although they seem to represent a sizable population based on recent demographic trends on SAHFs (Livingston, 2018). 
Furthermore, the research does not capture how identities may shift over time, as family needs also shift. For example, little is known about men's transition from a SAHF role back into the workforce. Research also does not capture dynamics of change, for example, as fathers and mothers may shift back and forth in their caregiving responsibilities over time. There is a need to broaden the image of SAHFs and ensure the full range of SAHFs and their diverse experiences are included in our studies.

Parenting Needs, Mental Health, and WellBeing of SAHFs There is a need for more quantitative research on the parenting needs and well-being of SAHFs, however the group of SAHFs is defined. Currently there is little knowledge about the health, well-being, and parenting of SAHFs who adopt primary caregiving roles, while working part-time or not working at all. Qualitative studies point to numerous strengths of SAHFs, and SAHFs themselves point to many benefits of this role; however, few studies have investigated these issues with larger and more representative populations. For example, even though a number of qualitative studies pointed to social isolation as a factor that SAHFs often have to deal with, it is not clear how and if such feelings of social isolation relate to poorer mental health or well-being of SAHFs.

\section{Child Well-Being and Father-Child} Relationships In our review of the literature, we noted one perspective that was particularly absent in the research on SAHFs - that of their children. While paternity leave is altogether different from the decision to become a SAHF, a study by Petts and colleagues (2019) examined paternity leave taking and child well-being. This study found positive outcomes for fathers who took paternity leave. Specifically, fathers who took 2 weeks or more of paternity leave had children who, as teenagers, reported more frequent involvement with their fathers, greater closeness, and better communication (Petts et al., 2019). Although the effect sizes were small, this study provided some of the only evidence to date regarding the potential benefits to children of paternity leave. Such leave was also associated with better parental relationship and positive fathering identity (Petts et al., 2019). It is notable that few to no studies examined outcomes or experiences of children who grow up with a SAHF. It would be interesting to examine the SAHF caregiving experience from the perspective of fathers and mothers, as well as their children. For example, researchers could ask children to retrospectively reflect on the experience of having a SAHF in order to consider this unique caregiving experience from those who may have the most intimate knowledge of the benefits and potential challenges.

\section{Key Points}

- Although there is a great deal more to be learned about stay-at-home fathers, the literature reviewed in this chapter suggests six key points: Although the official US Census Bureau statistics indicate that there are relatively few stay-athome fathers in the USA, the official definition likely greatly underestimates the number of fathers who are primary caregivers to children.

- Whether using official US Census Bureau statistics or other sources of data, there is evidence that the number of stay-at-home fathers has been rising in the past 15-20 years.

- Stay-at-home fathers tend to come from higher-income households and have higher levels of education when compared to the US population overall.

- One common theme that is captured in the qualitative research on stay-at-home fathers is that some fathers report feeling isolated in their role as a full-time stay-at-home caregiver. Research also suggests feelings of and experiences that speak to gender role conflict.

- Although the empirical evidence is not definitive, it seems that the mental health and well-being of stay-at-home 
fathers is better than or comparable to other men, but that shifting from working to a stay-at-home father role may be more difficult for fathers as compared to mothers.

- The research on stay-at-home fathers is lacking in diversity, with most studies focusing on the experiences of middleand upper-income, white, heterosexual men.

\section{References}

Ammari, T., \& Schoenebeck, S. (2016). "Thanks for your interest in our Facebook group, but it's only for dads": Social roles of stay-at-home dads. Paper presented at the Computer Supported Cooperative Work and Social Computing, San Francisco, CA.

Ashwin, S., \& Lytkina, T. (2016). Men in Crisis in Russia. Gender \& Society 18(2),189-206.

Barnett, R. C., \& Hyde, J. S. (2001). Women, men, work, and family: An expansionist theory. American Psychologist, 56, 781-796. https://doi. org/10.1037/0003-066X.56.10.781

Blom, N., \& Hewitt, B. (2020). Becoming a FemaleBreadwinner Household in Australia: Changes in Relationship Satisfaction. Journal of Marriage and Family 82(4), 1340-1357.

Burkstrand Reid, B. A. (2012). Dirty Harry meets dirty diapers: Masculinities, at home fathers, and making the law work for families. Texas Journal of Women \& the Law, 22, 1-44.

Cameron, C. (2001). Promise or problem? A review of the literature on men working in early childhood services. Gender, Work and Organization, 8, 430-453. https:// doi.org/10.1111/1468-0432.00140

Caperton, W., Butler, M., Kaiser, D., Connelly, J., \& Knox, S. (2020). Stay-at-home fathers, depression, and help-seeking: A consensual qualitative research study. Psychology of Men \& Masculinities, 21, 235250. https://doi.org/10.1037/men0000223

Connell, R. W. (1995). Masculinities. Berkeley, CA: University of California Press.

Chesley, N. (2011). Stay-at-home fathers and breadwinning mothers: Gender, couple dynamics, and social change. Gender \& Society, 25, 642-664. https://doi. org/10.1177/0891243211417433

Deutsch, F. M., \& Saxon, S. E. (1998). The double standard of praise and criticism for mothers and fathers. Psychology of Women Quarterly, 22, 665-683. https:// doi.org/10.1111/j.1471-6402.1998.tb00184.x

Doucet, A. (2004). "It's almost like I have a job but I don't get paid": Fathers at home reconfiguring work, care, and masculinity. Fathering, 2, 277-303. https://doi. org/10.3149/fth.0203.277

Feinberg, M. E., Jones, D. E., Kan, M. L., \& Goslin, M. C. (2010). Effects of family foundations on parents and children: 3.5 years after baseline. Journal of Family Psychology, 24, 532-542. https://doi.org/10.1037/ a0020837

Goodman, J. H. (2005). Becoming an involved father of an infant. Journal of Obstetric, Gynecologic, \& Neonatal Nursing, 34, 190-200. https://doi. org/10.1177/0884217505274581

Henry, G. (2017). Glen Henry: What I've learned about parenting as a stay-at-home-dad [Video file]. Retrieved from https://www.ted.com/talks/glen_henry_ what_i_ve_learned_being_a_stay_at_home_dad/ footnotes?language $=$ en

Kaplan, A., \& Garner, J. K. (2017). A complex dynamic systems perspective on identity and its development: The dynamic systems model of role identity. Developmental Psychology, 53, 2036-2051. https:// doi.org/10.1037/dev0000339

Knoester, C., Petts, R. J., \& Pragg, B. (2019). Paternity leave-taking and father involvement among socioeconomically disadvantaged U.S. fathers. Sex Roles, 81, 257-271. https://doi.org/10.1007/s11199-018-0994-5

Kramer, K. Z., Kelly, E. L., \& McCulloch, J. B. (2013). Stay-at-home fathers: Definition and characteristics based on 34 years of CPS data. Journal of Family Issues, 36, 1651-1673. https://doi.org/10.1177/01925 13X13502479

Kramer, K. Z., Kelly, E. L., \& McCulloch, J. B. (2015). Stay-at-home fathers: Definition and characteristics based on 34 years of CPS data. Journal of Family Issues, 36, 1651-1673. https://doi.org/10.1177/01925 $13 X 13502479$

Kramer, K. Z., \& Kramer, A. (2016). At home father families in the United States: Gender ideology, human capital, and unemployment. Journal of Marriage and Family, 78, 1315-1331. https://doi.org/10.1111/ jomf. 12327

Kramer, K. Z., \& Pak, S. (2018). Relative earnings and depressive symptoms among working parents: Gender differences in the effect of relative income on depressive symptoms. Sex Roles, 78, 74-759. https://doi. org/10.1007/s11199-017-0848-6

Latshaw, B. A. (2011). Is fatherhood a full-time job? Mixed methods insights into measuring stay-athome fatherhood. Fathering, 9, 125-149. https://doi. org/10.3149/fth.0902.125

Lee, J. Y., Knauer, H. A., Lee, S. J., MacEachern, M. P., \& Garfield, C. F. (2018). Father-inclusive perinatal parent education programs: A systematic review. Pediatrics, 142, 1-18. https://doi.org/10.1542/peds.2018-0437

Lee, J. Y., \& Lee, S. J. (2018). Caring is masculine: Stayat-home fathers and masculine identity. Psychology of Men \& Masculinity, 19, 47-58. https://doi. org/10.1037/men0000079

Liong, M. (2017). Sacrifice for the family: Representation and practice of stay-at-home fathers in the intersection of masculinity and class in Hong Kong. Journal 
of Gender Studies, 26, 402-417. https://doi.org/10.108 $0 / 09589236.2015 .1111200$

Livingston, G. (2014). Growing number of dads home with the kids: Biggest increase among those caring for family. Retrieved from https:// www.pewsocialtrends.org/2014/06/05/ growing-number-of-dads-home-with-the-kids/

Livingston, G. (2018). About 1 in 5 U.S. moms and dads are stay-at-home parents. Retrieved from https://www. pewresearch.org/fact-tank/2018/09/24/stay-at-homemoms-and-dads-account-for-about-one-in-five-u-sparents/

Lundahl, B., Tollefson, D., Risser, H., \& Lovejoy, M. C. (2008). A meta-analysis of father involvement in parent training. Research on Social Work Practice, 18, 97-106. https://doi.org/10.1177/1049731507309828

May, C., \& Fletcher, R. (2013). Preparing fathers for the transition to parenthood: Recommendations for the content of antenatal education. Midwifery, 29, 474478. https://doi.org/10.1016/j.midw.2012.03.005

McGinn, K. L., \& Oh, E. (2017). Gender, social class, and women's employment. Current Opinion in Psychology, 18, 84-88. https://doi.org/10.1016/j. copsyc.2017.07.012

Merla, L. (2008). Determinants, costs, and meanings of Belgian stay-at-home fathers: An international comparison. Fathering: A Journal of Theory, Research \& Practice about Men as Fathers, 6, 113-132. https:// doi.org/10.3149/fth.0602.113

National Center for Education Statistics. (2018). Fast facts: Educational attainment. Retrieved from https:// nces.ed.gov/fastfacts/display.asp?id=27

Ohanian, A. (2019). Paternity leave was crucial after the birth of my child, and every father deserves it. The New York Times. Retrieved from https://parenting.nytimes.com/work-money/ alexis-ohanian-paternity-leave

O'Neil, J. M. (2013). Gender role conflict research 30 years later: An evidence-based diagnostic schema to assess boys and men in counseling. Journal of Counseling \& Development, 91, 490-498. https://doi. org/10.1002/j.1556-6676.2013.00122.x

Parker, K., \& Livingston, G. (2019). 8 facts about American dads. Retrieved from https://www.pewresearch.org/fact-tank/2018/06/13/fathers-day-facts/

Parry, D. C., Glover, T. D., \& Mulcahy, C. M. (2013). From "stroller stalker" to "momancer": Courting friends through a social networking site for mothers. Journal of Leisure Research, 45, 22-45. https://doi. org/10.18666/j1r-2013-v45-i1-2941

Petts, R. J., Knoester, C., \& Waldfogel, J. (2019). Fathers' paternity leave-taking and children's perceptions of father-child relationships in the United States. Sex Roles, 82, 173-188. https://doi.org/10.1007/ s11199-019-01050-y

Plantin, L., Mansson, S., \& Kearney, J. (2003). Talking and doing fatherhood: On fatherhood and masculinity in Sweden and England. Fathering, 1, 3-26.
Rochlen, A., \& Mahalik, J. R. (2004). Women's perceptions of male partner's gender role conflict as predictors of psychological well-being and relationship satisfaction. Psychology of Men and Masculinity, 5, 147-157. https://doi.org/10.1037/1524-9220.5.2.147

Rochlen, A. B., McKelley, R. A., Suizzo, M. A., \& Scaringi, V. (2008). Predictors of relationship satisfaction, psychological Well-being, and life satisfaction among stay-at-home fathers. Psychology of Men \& Masculinity, 9, 17. https://doi. org/10.1037/1524-9220.9.1.17

Rochlen, A. B., McKelley, R. A., \& Whittaker, T. A. (2010). Stay-at-home fathers' reasons for entering the role and stigma experiences: A preliminary report. Psychology of Men \& Masculinity, 11, 279-285. https://doi.org/10.1037/a0017774

Rushing, C., \& Powell, L. (2015). Family dynamics of the stay-at-home father and working mother relationship. American Journal of Men's Health, 9, 410-420. https://doi.org/10.1177/1557988314549414

Snitker, A. (2018). Not Mr. mom: Navigating discourses for stay-at-home fathers. The Journal of Men's Studies, 26, 203-221. https://doi. org/10.1177/1060826518758628

Solomon, C. R. (2014). "After months of it, you just want to punch someone in the face": Stay-at-home fathers and masculine identities. Michigan Family Review, 18, 23-38. https://doi.org/10.3998/mfr.4919087.0018.103

Steinhour, H. (2018). I am not "Mr. mom": A qualitative analysis of at-home father's struggle for legitimacy. Journal of Gender Studies, 27, 388-400. https://doi. org/10.1080/09589236.2016.1220290

StGeorge, J. M., \& Fletcher, R. J. (2011). Fathers online: Learning about fatherhood through the internet. The Journal of Perinatal Education, 20, 154-162. https:// doi.org/10.1891/1058-1243.20.3.154

Terrazas, A. (2018). Rising trend of stay-at-home dads hits all-time high. Retrieved from https://www.zillow. com/research/stay-at-home-dads-20190/

U.S. Bureau of Labor Statistics. (2018). Employment status of the civilian noninstitutional Population 16 years and over by sex, 1970s to date [PDF file]. Retrieved from https://www.bls.gov/cps/cpsaat02.pdf

U.S. Bureau of Labor Statistics. (2019). Employment characteristics of families-2018 [PDF file]. Retrieved from https://www.bls.gov/new.release/pdf/famee

U.S. Census Bureau. (2018). America's families and living arrangements [Data file]. Retrieved from https:// www.census.gov/data/tables/2018/demo/families/cps2018.html

Yogman, M., \& Garfield, C. F. (2016). Fathers' roles in the care and development of their children: The role of pediatricians. Pediatrics, 138, 1-15. https://doi. org/10.1542/peds.2016-1128

Zimmerman, T. S. (2000). Marital equality and satisfaction in stay-at-home mother and stay-at-home father families. Contemporary Family Therapy, 22, 337-354. https://doi.org/10.1023/A:1007816725358 